\title{
Advances in the study of nano-structured Co/MCM-41 materials: surface and magnetic characterization
}

\author{
Verónica R. Elías ${ }^{1} \cdot$ Natalia I. Cuello $^{1} \cdot$ Leandro Andrini $^{2} \cdot$ Félix G. Requejo $^{2} \cdot$ \\ Marcos I. Oliva ${ }^{3} \cdot$ Griselda A. Eimer $^{1}$
}

(C) Springer Science+Business Media, LLC 2017

\begin{abstract}
Co-modified mesoporous supports with MCM41 structure and several metal loadings were successfully synthesized by a fast wet impregnation method. The nature and location of different Co species formed on the solids were inferred by TEM/SEM, XPS, XANES/EXAFS, adsorption of pyridine coupled to FT-IR spectroscopy and temperature dependence of magnetization. The presence of Co oxide species (clusters and $\mathrm{Co}_{3} \mathrm{O}_{4}$ nanoparticles) inside the channels of all the samples could be evidenced by TEM, XPS and XANES/EXAFS. In this sense, the surface $\mathrm{Co} / \mathrm{Si}$ atomic ratios obtained by XPS were notably lower than the corresponding bulk $\mathrm{Co} / \mathrm{Si}$ ratios obtained by ICP, indicating that the $\mathrm{Co}$ atoms are mostly incorporated inside the mesopores channels of the silica matrix. Nevertheless, by TEM, $\mathrm{Co}_{3} \mathrm{O}_{4}$ nanoparticles of small size segregated on the external surface of the silicate were also observed for the higher metal loadings. The temperature dependence of the magnetization performed for the $\mathrm{Co} / \mathrm{M}(2.5)$ sample allowed to assign its
\end{abstract}

Electronic supplementary material The online version of this article (doi:10.1007/s10934-017-0492-0) contains supplementary material, which is available to authorized users.

Griselda A. Eimer

geimer@frc.utn.edu.ar

Verónica R. Elías

veroelias@gmail.com

1 Centro de Investigación y Tecnología Química (CITeQ) (UTN-CONICET), Facultad Regional Córdoba, Maestro López y Cruz Roja Argentina, Ciudad Universitaria, 5016 Córdoba, Argentina

2 Instituto de Física de La Plata, CCT La Plata, CONICET-Dpto de Física, Fac. Cs. Exactas, Universidad Nacional de La Plata, La Plata, Argentina

3 IFEG-CONICET -FaMAF-Universidad Nacional de Córdoba, Córdoba, Argentina superparamagnetic behavior to the presence of clusters and $\mathrm{Co}_{3} \mathrm{O}_{4}$ nanoparticles of very small size that grow inside the MCM-41 mesopores. Therefore, the analyses presented in this work indicate that a Co theoretical loading of $2.5 \mathrm{wt} \%$ leads to the formation of Co oxide nanospecies in the MCM41 support with a particular superparamagnetic behavior. This sample with improved structural and magnetic properties result an attractive porous solid for drug hosting, to be applied in the field of the controlled release of medicaments.

Keywords EXAFS/XANES - Magnetic properties . XPS $\cdot$ Surface properties

\section{Introduction}

Mesoporous molecular sieves modified with metal oxides have different applications such as supports for gas sensors, electrode materials for batteries, supercapacitors, fuels cells, sorbents for separation, media for gas storage and drug delivery [1-6]. In this sense, Co is one of the transition metals extensively studied for their interesting properties. Regarding the novel applications, Co oxide has showed a good electrochemical performance in terms of specific capacity and cyclability [7] and nanosized $\mathrm{Co}_{3} \mathrm{O}_{4}$ has exhibited high capacitance as electrode in supercapacitors. Moreover, supported Co oxides on mesoporous materials are of wide interest for their known applications in several areas. Thus, they have been used as catalysts for the Fischer Tropsch reaction, for the combustion of volatiles organic compounds $[8,9]$ as well as for other kinds of reactions because of their large specific areas and shape selective properties [10]. For its part, in view of their technological importance, the synthesis of magnetic systems with characteristic nanoscale dimensions has attracted much attention in the research field [11, 
12]. Particularly, magnetic nanoparticles offer some attractive possibilities in biomedicine. One of the most important features of them is the possibility of controlling their size from a few nanometers up to tens of nanometers. Then, they reach dimensions comparable to those of biological entities allowing interacting with them, providing a controllable mean of tagging. In addition, the fact that the nanoparticles have magnetic properties opens the possibility to manipulate them with an external magnetic field gradient in order to make: delivering package such as anticancer drugs to a targeted region of the body such as a tumor, hyperthermia treatments, and magnetic resonance imaging contrast enhancements [13]. Meanwhile, the MCM-41 structure of mesoporous silicates, with a highly ordered structure of channels of well-defined size, is particularly suitable for the synthesis of nanospecies with magnetic properties. Bearing in mind the previous discussion, in this work we extend the study about Co nanospecies with magnetic properties loaded on MCM-41 silicates. Thus, the focus of this work is on its thorough identification, location and acidic properties in relation to their magnetic behavior through the application of specific spectroscopic techniques.

\section{Experimental}

\subsection{Synthesis}

The bare MCM-41 support was synthesized following the method already descript in our previous report [14] using cetyltrimethylammonium bromide (CTA) as template and tetraethoxysilane (TEOS) as silicon source. Then, the silicate matrix was modified with Co by the wet impregnation method using several concentrations of $\mathrm{Co}\left(\mathrm{NO}_{3}\right)_{2} \cdot 6 \mathrm{H}_{2} \mathrm{O}$ in aqueous solution in order to reach metal loadings of 1.0, 2.5, $5.0,10.0$ and $15.0 \mathrm{wt} \%$. Then, water was evaporated and the solids calcined at $773 \mathrm{~K}$ for $9 \mathrm{~h}$ [15]. The calcined materials were designated as $\mathrm{Co} / \mathrm{M}(\mathrm{x})$ where $\mathrm{M}$ indicates the presence of the MCM-41 structure and $x$ indicates the nominal percentage of the metal loading.

\subsection{Characterization}

The Co content was determined by inductively coupled plasma optical emission spectroscopy (ICP) using an equipment VISTA-MPX CCD Simultaneus ICP-OES-VARIAN.

SEM micrographs were obtained in a JEOL model JSM $6380 \mathrm{LV}$. Gold coverage was applied to make samples conductive. The acceleration voltage was $20 \mathrm{kV}$. TEM images were obtained in a JEOL Model JEM-1200 EXII System, working voltage: $120 \mathrm{kV}$. A small drop of the dispersion (sample in water-ethanol 50\% solution) was deposited on a copper grid and then evaporated in air at room temperature.

Co K-XANES/EXAFS spectra were acquired in transmission mode by using a Double Crystal Si(111) monochromator at the D08B-XAFS2 beamline of the LNLS (Campinas, Brazil) [16-20]. Powder samples were mixed with an appropriate amount of boron nitride and pressed into pellets. The incident photon energy was in the range of $7630-8700 \mathrm{eV}$ with an energy resolution about $1.2 \mathrm{eV}$. The ionization chambers were filled with $\mathrm{N}_{2} / \mathrm{Ar}_{2}$ mixture under appropriate pressure for optimal absorption. For energy calibration purposes a Co metallic foil was placed between the second and the third ionization chamber. The photon energy was calibrated setting the first inflection point to the energy of the $\mathrm{K}$ absorption edge of metallic $\mathrm{Co}^{0}(7709 \mathrm{eV})$. Data reduction was carried out with Demeter package programs [21].

$\mathrm{X}$-ray photoelectron spectra (XPS) were carried out in a multi-technical system (SPECS) equipped with a dual X-ray source Mg/Al model XR50, which has a hemispheric analyzer PHOIBOS 150 operating in fix analyzer transmission mode (FAT). Spectra were acquired with pass energy of $30 \mathrm{eV}$, using $\mathrm{Al}$ anode operated at $100 \mathrm{~W}$. Work pressure in analysis chamber was lower than $2.10^{-8} \mathrm{mbar}$. Binding energy values were corrected using as reference the adventitious $\mathrm{C} 1 \mathrm{~s}$ line at $284.6 \mathrm{eV}$. The original XPS spectra were fitted by Gaussian curves using the conventional least squares method. Curve-fitting calculations were useful in determining each band location with confidence levels given by $\mathrm{R}^{2} \geq 0.99$.

FT-IR spectral measurements of pyridine adsorption on the samples were performed on a JASCO FT-IR 5300 spectrometer equipped with a DTGS detector. The range and resolution of acquisition data were $4600-400$ and $4 \mathrm{~cm}^{-1}$, respectively. A self-supporting wafer for each sample ( $\sim 20 \mathrm{mg}$ and $13 \mathrm{~mm}$ of diameter) was prepared, placed in a thermostatted cell with $\mathrm{CaF}_{2}$ windows connected to a vacuum line, and evacuated for $8 \mathrm{~h}$ at $673 \mathrm{~K}$. The background spectrum was recorded first after cooling the sample to room temperature. Afterward, the solid wafer was exposed to pyridine vapors (Sintorgan, 99\% purity) until the system was saturated to $\sim 46 \mathrm{mmHg}$ at room temperature; the contact time at this pressure was $12 \mathrm{~h}$. The FT-IR spectrum for each sample was obtained after pyridine desorption by evacuation for $1 \mathrm{~h}$ at 473 or $573 \mathrm{~K}$. All the spectra were recorded at room temperature before and after pyridine adsorption and desorption at each temperature.

The temperature dependence of the magnetization was measured following the conventional zero field cooling (ZFC) and the field cooling (FC) protocols, using a Quantum Design SQUID magnetometer MPMS XL7 with static field up to $\mu_{0} \mathrm{H}=10 \mathrm{mT}$. 


\section{Results and discussion}

The chemical composition and physical properties of all of the synthesized materials are shown in Table S1. A discussion of these data have been reported previously, and they are also added here in order to support the discussion presented in this report (see also Fig. S1) [15].

Then, TEM images of some $\mathrm{Co} / \mathrm{M}(\mathrm{x})$ samples are shown in Fig. 1. As it can be observed, it could be confirmed the presence of the well-ordered parallel straight mesochannels, characteristic of the hexagonal pore arrangement, present in the samples. In this sense, the images of Fig. $1 \mathrm{c}, \mathrm{h}$ are views perpendicular to the direction of the hexagonal pore arrangement, where the straight mesochannels arraying along the long axis are shown [22-24]. For its part, a frontal view of the pores can be observed in Fig. 1a, d, f, g, where the regular order of the channels is preserved without being affected by the presence of Co species. In agreement with these observations, the already reported XRD patterns for $\mathrm{Co} / \mathrm{M}(\mathrm{x})$ samples (Fig. S2) [15] show that the mesoporous order is sustained after the Co loading for all the metal contents. Moreover, no peaks corresponding to Co oxides appear in the high-angle XRD patterns (Fig. S3) for the lower Co loaded samples indicating that these species are amorphous or are clusters/particles too small to be detected by XRD. For its part, since the darker areas in TEM images represent the electronically more dense phases, metal oxide is considered to be present when irregular contrasts in the images are observed [25]. Thus, in Figs. $1 \mathrm{~g}$ and $1 \mathrm{~h}$ corresponding to samples with high Co loading, the incorporation of the cobalt oxide species inside the mesoporous channels could be confirmed. In fact, the impregnation with a high amount of Co nitrate followed by a calcination at $773 \mathrm{~K}$, results in the formation of clusters or very small particles of oxide within the mesoporous silica channels evidenced by the darker regions along the mesopores [26].

The particle size and morphology of $\mathrm{Co} / \mathrm{M}(\mathrm{x})$ samples were investigated by scanning electron microscopy. Figure 2 shows the SEM images of all of the samples. Here, particles with spherical-like morphology aggregated into larger
Fig. 1 Transmission electron microscopy images: $(\mathbf{a}-\mathbf{b}-\mathbf{c})$ $\mathrm{Co} / \mathrm{M}(1),(\mathbf{d}-\mathbf{e}) \mathrm{Co} / \mathrm{M}(2.5),(\mathbf{f}-$ g) $\mathrm{Co} / \mathrm{M}(5)$ and (h) $\mathrm{Co} / \mathrm{M}(15)$
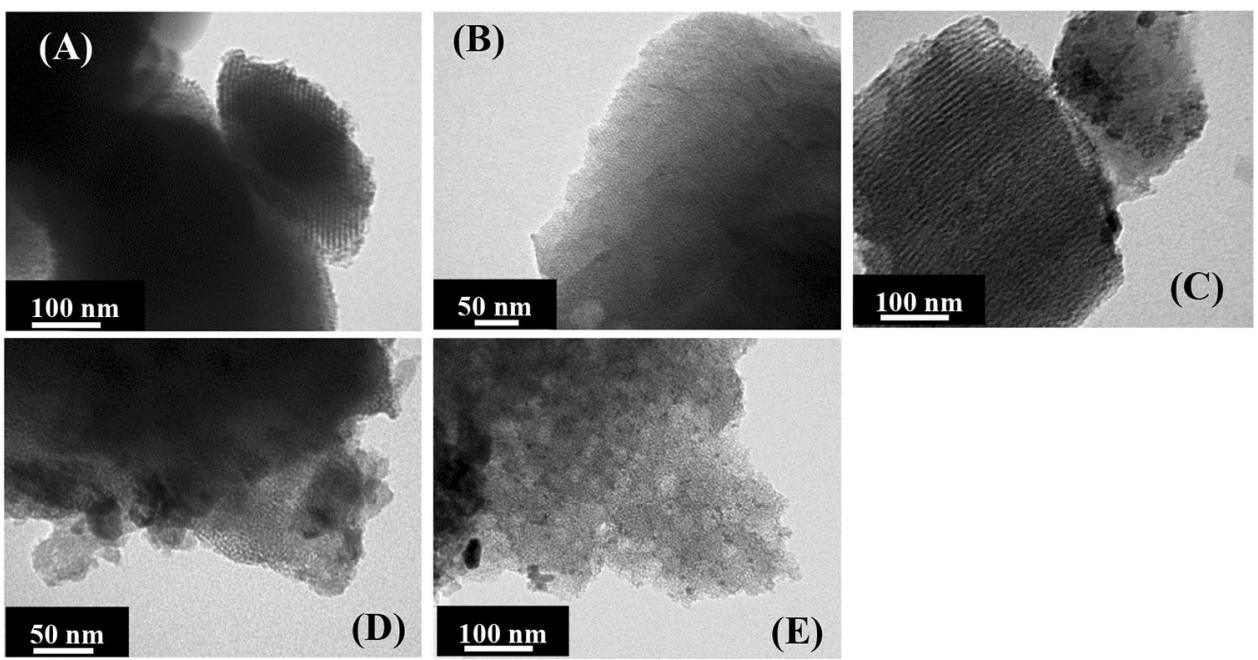

$100 \mathrm{~nm}$

(E)
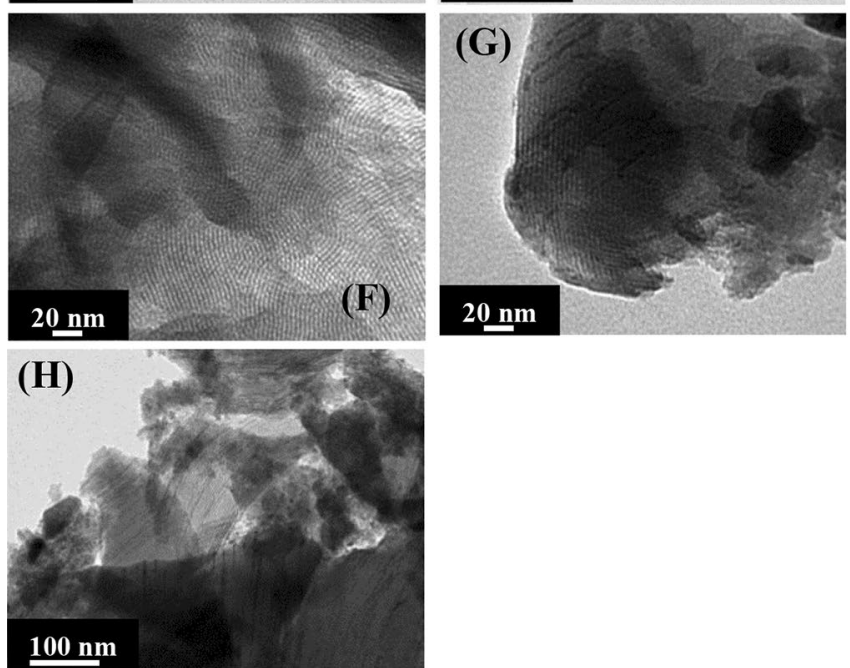
Fig. 2 Scanning electron microscopy images: a $\mathrm{Co} / \mathrm{M}(1)$, b $\mathrm{Co} / \mathrm{M}(2.5)$, c $\mathrm{Co} / \mathrm{M}(5), \mathbf{d}$ $\mathrm{Co} / \mathrm{M}(10)$ and e $\mathrm{Co} / \mathrm{M}(15)$
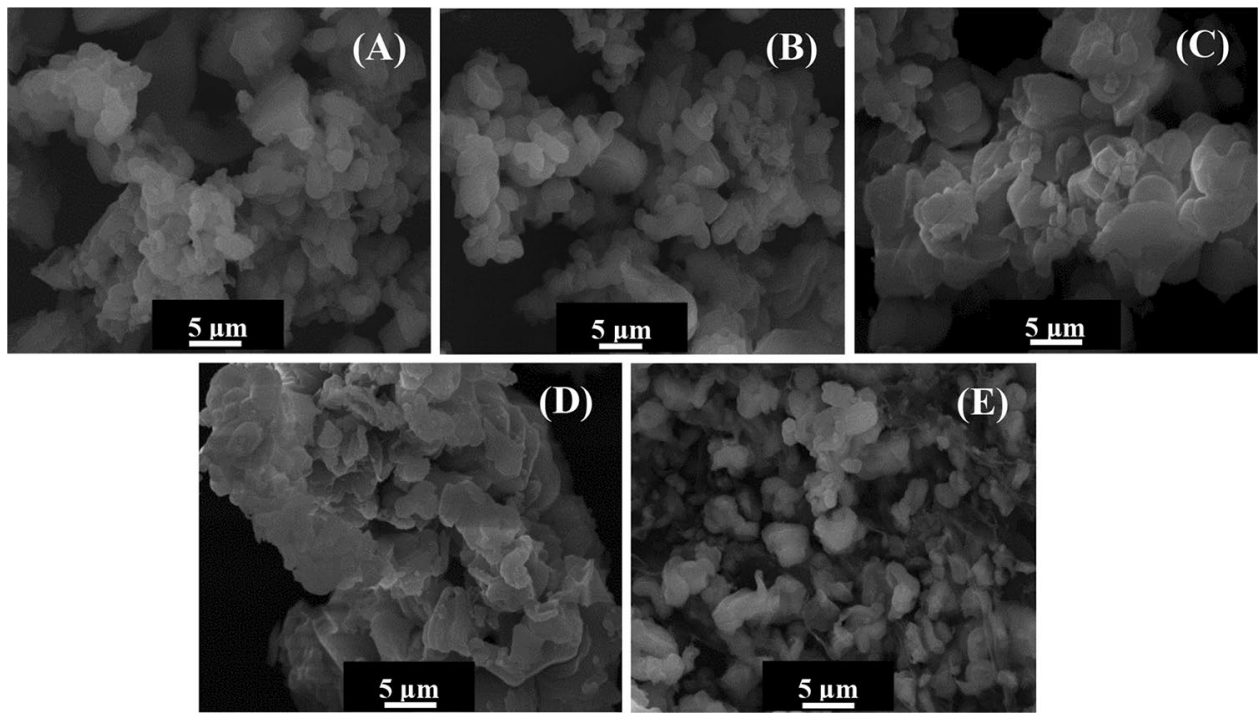

secondary particles that exist in various morphologies and sizes could be observed [28-30].

This irregular morphology could be consequence of the metal oxides deposited on the silica matrix at several locations which provoke the agglomeration. This kind of morphology was already observed for MCM-41 silicates modified with $\mathrm{Cr}$ and $\mathrm{Ti}[27,31]$.

In order to study the chemical state and relative abundance of the elements on the solid surface, photoelectron spectroscopy was used. Figure 3 illustrates the Co $2 p$ region of the X-ray photoelectron spectra of $\mathrm{Co} / \mathrm{M}(\mathrm{x})$ samples with nominal Co loadings from 1.0 to $15.0 \mathrm{wt} \%$. As it could be observed, the Co2p transition splits into two peaks, $2 \mathrm{p} 3 / 2$ $(780.5 \mathrm{eV})$ and 2p1/2 (795.4 eV) with a spin-orbit splitting of around $15.0 \mathrm{eV}$, which is in accordance with data reported in the literature [32-34].

Nevertheless, it is known that it is difficult to determine the Co cations oxidation states only from the binding energies (BE) of the Co2p main lines, because similar values can be obtained for most of the Co oxides and hydroxides $\left(\mathrm{CoO}, \mathrm{Co}_{2} \mathrm{O}_{3}, \mathrm{Co}_{3} \mathrm{O}_{4}, \mathrm{CoOOH}\right)$. Then, satellite peak information should be considered. In this sense, it is generally accepted that energy gaps, between the Co2p main lines and the satellites peaks, are highly related to the oxidation states of Co cations. Thus, as it can be observed in Fig. 3, the relatively sharp peak width, the $2 \mathrm{p} 1 / 2$ to $2 \mathrm{p} 3 / 2$ separation of around $15 \mathrm{eV}$ and the energy gaps between the main lines and their satellite peaks indicate the co-existence of $\mathrm{Co}^{2+}$ and $\mathrm{Co}^{3+}$ on the surface of the solids. For its part according to the literature, the two satellite peaks detected at about $6 \mathrm{eV}(785.5 \mathrm{eV})$ and $9-10 \mathrm{eV}(790 \mathrm{eV})$ above the Co2p3/2 main line could be assigned to Co cation valence of $2+$ and $3+$ present in the $\mathrm{Co}_{3} \mathrm{O}_{4}$ structure [35]. In this sense, the spectra of the samples synthesized in this work are similar to those corresponding to $\mathrm{Co}_{3} \mathrm{O}_{4}$ oxide, which has two types

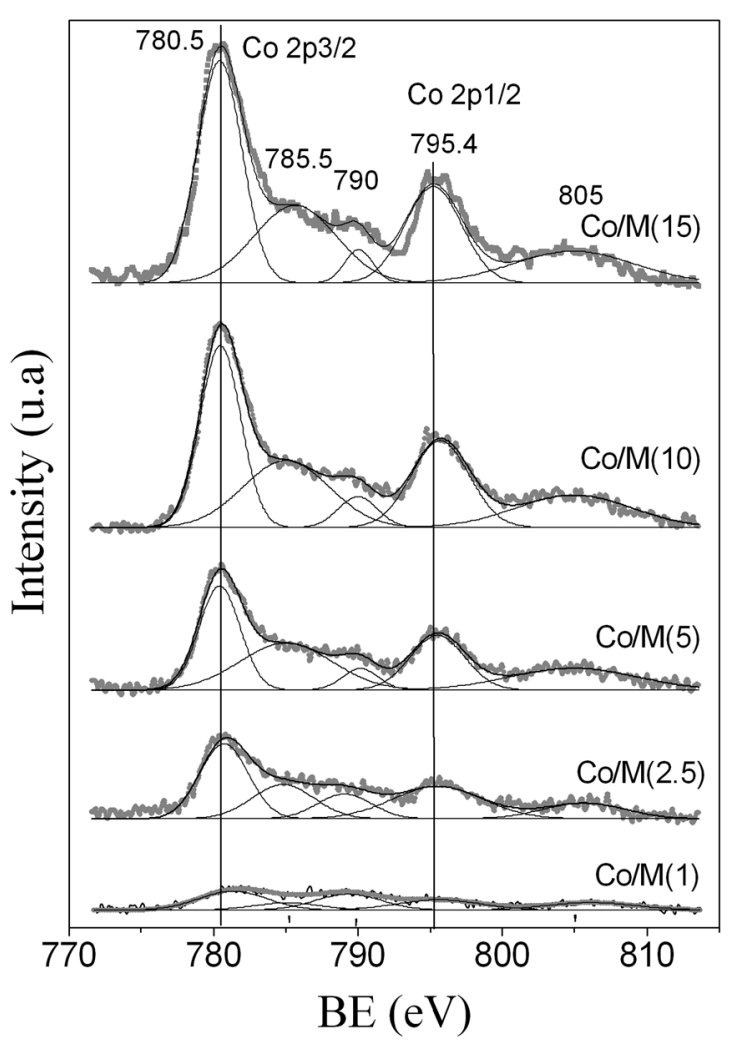

Fig. 3 Co $2 p$ core level photoelectron profile of $\mathrm{Co} / \mathrm{M}(\mathrm{x})$ samples

of Co ions, tetrahedral $\mathrm{Co}^{2+}$ and octahedral $\mathrm{Co}^{3+}$ [36].This behavior was already observed for materials calcined at high temperatures (higher than $673 \mathrm{~K}$ ) where the weak satellites in the spectra were associated to the presence of the $\mathrm{Co}^{3+}$ ions in octahedral sites that exist in the spinel cobaltite structure formed onto the mesoporous silicate [36]. Therefore, the XPS technique allowed confirming the presence of Co oxide 
in the form of $\mathrm{Co}_{3} \mathrm{O}_{4}$ already evidenced by UV-Vis DR [15]. It is important to note that, due to the low quantity of Co species in the surface (see Table 1), the characteristic Co $2 p$ signals are hardly differentiable in the $\mathrm{Co} / \mathrm{M}(1)$ sample.

On the other hand, for all of the synthesized solids, Table 1 lists the surface $\mathrm{Co} / \mathrm{Si}$ atomic ratios determined by XPS and the bulk atomic $\mathrm{Co} / \mathrm{Si}$ ratios determined by ICP. Generally, the surface $\mathrm{Co} / \mathrm{Si}$ atomic ratio can be considered as the relative dispersion of transition metal ions on the structure of porous supports. In this sense, the values of this ratio were compared with the bulk $\mathrm{Co} / \mathrm{Si}$ ratios [37]. For the $\mathrm{Co} / \mathrm{M}(\mathrm{x})$ samples, the surface $\mathrm{Co} / \mathrm{Si}$ atomic ratio increases with an increase in the bulk $\mathrm{Co} / \mathrm{Si}$ ratio in the solids. Nevertheless, for all of the Co contents the surface $\mathrm{Co} /$ $\mathrm{Si}$ ratio is notably lower than the corresponding bulk $\mathrm{Co} / \mathrm{Si}$ ratio, indicating that the $\mathrm{Co}$ atoms would be mostly incorporated inside the mesopores [26]. These results agree with the already observed by TEM analysis, where it could be observed the mesopores channels of the silica matrix filled with the Co oxide species.
Then, Fig. 4 shows the XPS spectra for the Si2p and O1s signals corresponding to the $\mathrm{Co} / \mathrm{M}(15)$ sample taken as representative.

The $\mathrm{Si} 2 \mathrm{p} \mathrm{BE}$ of around $103.8 \mathrm{eV}$ is characteristic of the MCM-41 silica. The XPS O1s spectra consist of two components with $\mathrm{BE}$ at around 530 and $533 \mathrm{eV}$ corresponding to oxygen atoms from Co oxide species and from the silica support, respectively. As it can be observed in Table 1, the photoemission $\mathrm{O} 1 \mathrm{~s}$ for all of the $\mathrm{Co} / \mathrm{M}(\mathrm{x})$ samples is mainly due to the contribution of oxygen from silica (higher than $90 \%$ ). This fact would be other evidence of the presence of Co oxide species inside the mesoporous structure of the sieves. Nevertheless, a slight increase in the O1s percentage from the Co oxide species is observed with the metallic loading increasing which is according to the increased presence of the Co oxide species in the surface.

Co K-edge XAFS is a powerful tool for investigating the speciation and coordination structures of Co species formed in the silica mesoporous supports modified by the loading of this metal. Particularly, XANES spectra are frequently used as a "fingerprinting" to recognize a tetrahedral coordination

Table 1 XPS binding energy (BE) values and surface atomic concentration of Co/MCM-41 samples

\begin{tabular}{|c|c|c|c|c|c|c|c|c|}
\hline \multirow[t]{2}{*}{ Sample } & \multirow[t]{2}{*}{$\mathrm{Co}^{\mathrm{a}}(\mathrm{wt} \%)$} & \multirow[t]{2}{*}{ Co bulk (at.\%) } & \multirow[t]{2}{*}{$\mathrm{Co} / \mathrm{Si}$ bulk } & \multirow[t]{2}{*}{ Co2p BE (eV) } & \multirow{2}{*}{$\begin{array}{l}\mathrm{Co}^{\mathrm{b}} \text { surface } \\
\text { (at.\%) }\end{array}$} & \multirow[t]{2}{*}{$\mathrm{Co} / \mathrm{Si}$ surface } & \multicolumn{2}{|l|}{$\mathrm{O} 1 \mathrm{~s} \mathrm{BE}(\mathrm{eV})$} \\
\hline & & & & & & & From $\mathrm{Co}_{\mathrm{x}} \mathrm{O}_{\mathrm{y}}$ & From silica \\
\hline $\mathrm{Co} / \mathrm{M}(1)$ & 0.80 & 0.27 & 0.008 & 780.5 & 0.14 & 0.004 & $530.2(0.42)^{\mathrm{c}}$ & $533.4(99.58)^{\mathrm{c}}$ \\
\hline $\mathrm{Co} / \mathrm{M}(2.5)$ & 2.20 & 0.76 & 0.023 & 779.6 & 0.29 & 0.009 & $530.2(1.11)^{\mathrm{c}}$ & $533.2(98.89)^{\mathrm{c}}$ \\
\hline $\mathrm{Co} / \mathrm{M}(5)$ & 4.35 & 1.52 & 0.046 & 779.9 & 0.46 & 0.015 & $530.5(2.95)^{\mathrm{c}}$ & $533.3(97.05)^{\mathrm{c}}$ \\
\hline $\mathrm{Co} / \mathrm{M}(10)$ & 8.81 & 3.17 & 0.098 & 780.2 & 1.29 & 0.039 & $530.4(4.05)^{\mathrm{c}}$ & $533.2(95.94)^{\mathrm{c}}$ \\
\hline $\mathrm{Co} / \mathrm{M}(15)$ & 11.90 & 4.38 & 0.137 & 780.2 & 1.92 & 0.060 & $530.4(5.24)^{\mathrm{c}}$ & $533.3(94.75)^{\mathrm{c}}$ \\
\hline
\end{tabular}

${ }^{\text {a }}$ Determined by ICP

${ }^{\mathrm{b}}$ Determined by XPS

${ }^{\mathrm{c}}$ Between parenthesis the percentage composition of each species is shown

Fig. 4 XPS spectra of (a) Si 2p and (b) $\mathrm{O} 1 \mathrm{~s}$ for the $\mathrm{Co} / \mathrm{M}(15)$ sample (taken as representative)
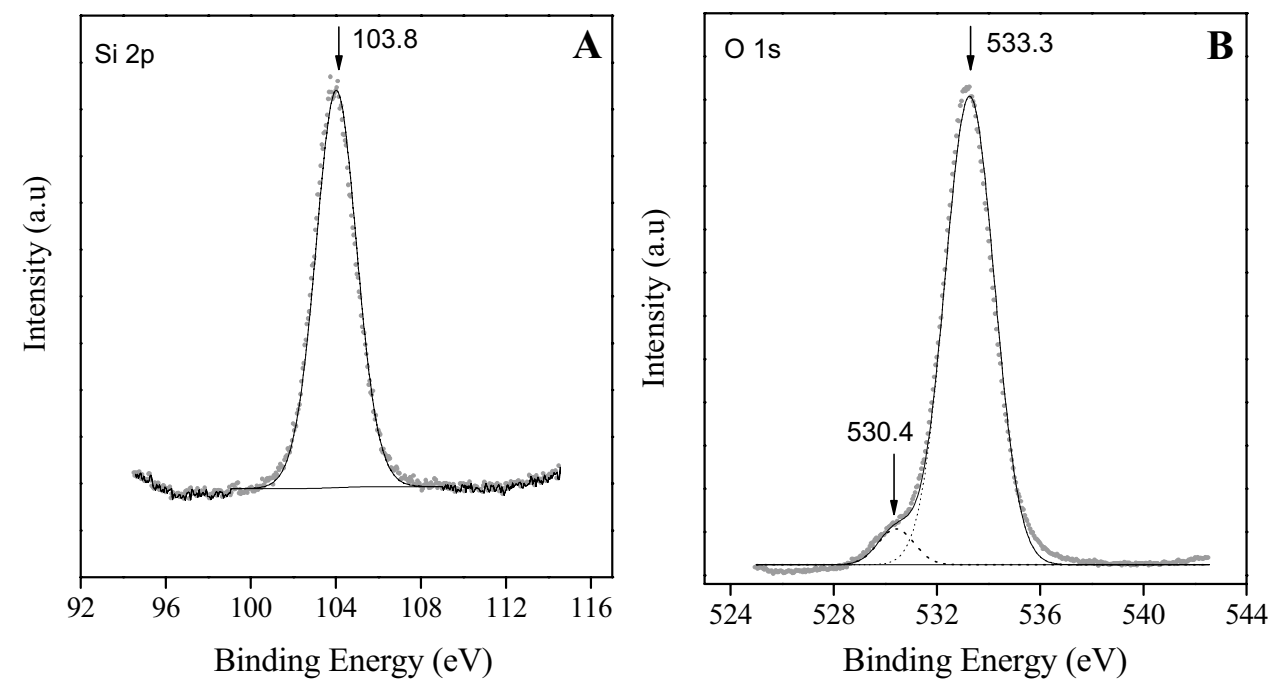
Fig. 5 A XANES spectra at the Co K edge for samples: $(a)$ $\mathrm{Co} / \mathrm{M}(5),(b) \mathrm{Co} / \mathrm{M}(10)$ and the following compounds used as references (c) $\mathrm{Co} 3 \mathrm{O} 4,(d) \mathrm{CoO}$ and $(e)$ Co0. B XANES spectra at the Co $\mathrm{K}$ edge for the $\mathrm{Co} 3 \mathrm{O} 4$ oxide and a detail of their most important characteristics

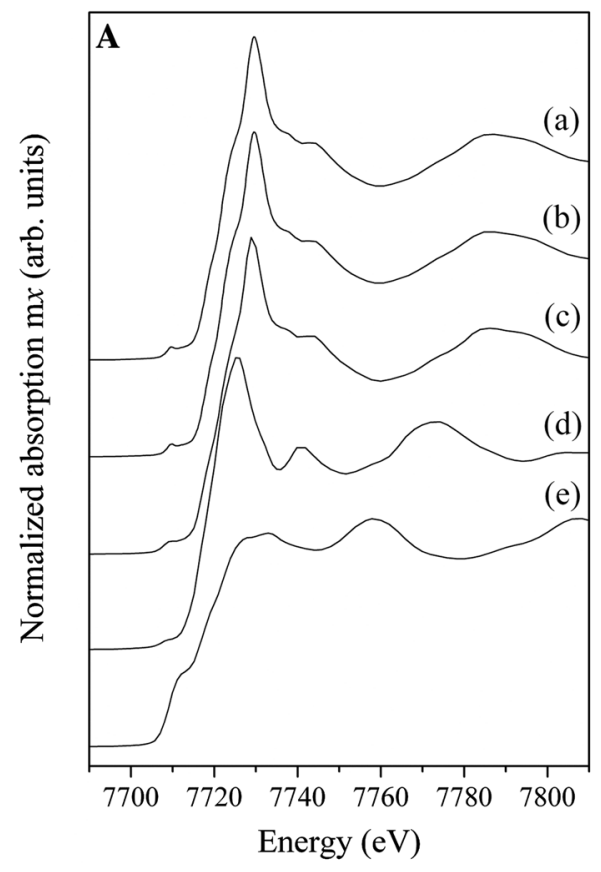

from an octahedral one [38] and changes in the average oxidation states $[39,40]$. Figure 5A shows the XANES spectra corresponding to the samples: $\mathrm{Co} / \mathrm{M}(5)$ (a), $\mathrm{Co} / \mathrm{M}(10)$ (b) and those from standards compounds used as references(c) $\mathrm{Co}_{3} \mathrm{O}_{4}$, (d) $\mathrm{CoO}$ and (e) metallic $\mathrm{Co}$. Figure 5B shows the Co $\mathrm{K}$ XANES spectra corresponding to the $\mathrm{Co}_{3} \mathrm{O}_{4}$ with spinel structure. In this last figure, the $\mathrm{A}$ region (pre-edge region) is closely associated to the $3 \mathrm{~d}$ electrons and to the symmetry. As it was mentioned before, it is known [41] that, at room temperature, the $\mathrm{Co}_{3} \mathrm{O}_{4}$ spinel has the presence of Co ions in tetrahedral and octahedral environments in a stoichiometric ratio of $\mathrm{Co}^{+2}\left[\mathrm{Co}^{+3}\right]_{2} \mathrm{O}_{4}$, and that $\mathrm{Co}^{+2}$ from $\mathrm{Co}_{3} \mathrm{O}_{4}$ oxide, tetrahedrally coordinated by $\mathrm{O}^{2-}$ ions, is different from the octahedrally coordinated $\mathrm{Co}^{+2}$ present in $\mathrm{CoO}$ oxide [42]

For the standard spinel structure analyzed in this work, the A pre-edge peak is attributed to a dipolar forbidden transition $1 \mathrm{~s}-3 \mathrm{~d}$ characteristic of the tetrahedrally coordinated $\mathrm{Co}^{+2}$ [43], because this transition is forbidden when there is a reversal center in the metal cation, as it is the case of the non-distorted octahedrally coordination. Moreover, the pre-edge in the $\mathrm{Co}_{3} \mathrm{O}_{4}$ spectra is assigned to the presence of tetrahedrally coordinated $\mathrm{Co}^{+2}$ [44] due also to the peaks of this ion are more intense than those of octahedral $\mathrm{Co}^{+3}$. This fact is due to the tetrahedral ligand field allows a dipolar transition, while in the octahedral symmetry, only a quadrupolar transition is allowed for $1 \mathrm{~s}-3 \mathrm{~d}$ [45]. Another characteristic is that the pre-edge peak of the octahedral site is usually wider than the one corresponding to a tetrahedral site [44, 45]. According to the reported by T. Jiang and D.E. Ellis [46], the A pre-edge region corresponds to the transition $1 \mathrm{~s}-3 \mathrm{~d}$ already described, the shoulders $\mathrm{B}$ and $\mathrm{C}$ correspond to contributions from multiple scattering in conjunction with the transition 1s-4s [44], the D peak corresponds to the allowed dipolar transition $1 \mathrm{~s}-4 \mathrm{p}$, and the resonances $\mathrm{E}$ and F correspond to contributions of multiple scattering. These are the main characteristics of the Co K XANES spectra of the spinel $\mathrm{Co}_{3} \mathrm{O}_{4}$ and, as it can be observed in Fig. 5A, the spectra of the two analyzed $\mathrm{Co} / \mathrm{M}(\mathrm{x})$ samples are similar to that corresponding to the $\mathrm{Co}_{3} \mathrm{O}_{4}$ oxide. Then, as it was evidenced by the other techniques used here, the presence of $\mathrm{Co}_{3} \mathrm{O}_{4}$ spinel on the MCM-41 silicates could be confirmed.

Figure 6 shows the normalized EXAFS signals, $k^{3} \chi(k)$, and their corresponding Fourier transforms for $\mathrm{Co} / \mathrm{M}(5)$, $\mathrm{Co} / \mathrm{M}(10)$ and the standard $\mathrm{Co}_{3} \mathrm{O}_{4}$.

Particularly, Fig. $6 \mathrm{~F}$ shows the features assigned to each maximum of the Fourier transform [47]. The first one corresponds to the $\mathrm{Co}-\mathrm{O}$ coordination sphere, the second one to the $\mathrm{Co}$ (II)-Co(II) coordination sphere (tetrahedrally coordinated), and the third one to the $\mathrm{Co}(\mathrm{III})-\mathrm{Co}$ (III) coordination sphere (octahedrally coordinated) [48]. By comparison with the signals corresponding to the standard $\mathrm{Co}_{3} \mathrm{O}_{4}$ oxide, the $\mathrm{Co} / \mathrm{M}(\mathrm{x})$ samples analyzed in this work show a decrease in the intensity corresponding to $\mathrm{Co}-\mathrm{Co}\left(\mathrm{T}_{\mathrm{d}}\right)$, which is more notable for the sample $\mathrm{Co} / \mathrm{M}(5)$, where there is also, a small variation in the intensity related to $\mathrm{Co}-\mathrm{Co}\left(\mathrm{O}_{\mathrm{h}}\right)$. This difference in the peak intensities (mainly for the lower loaded sample) with respect to the standard bulk oxide could be assigned to a certain disorder degree in the $\mathrm{Co}_{3} \mathrm{O}_{4}$ nanospecies present as clusters or nanoparticles of very small size, more finely dispersed and strongly interacting with the mesoporous matrix surface [48]. 


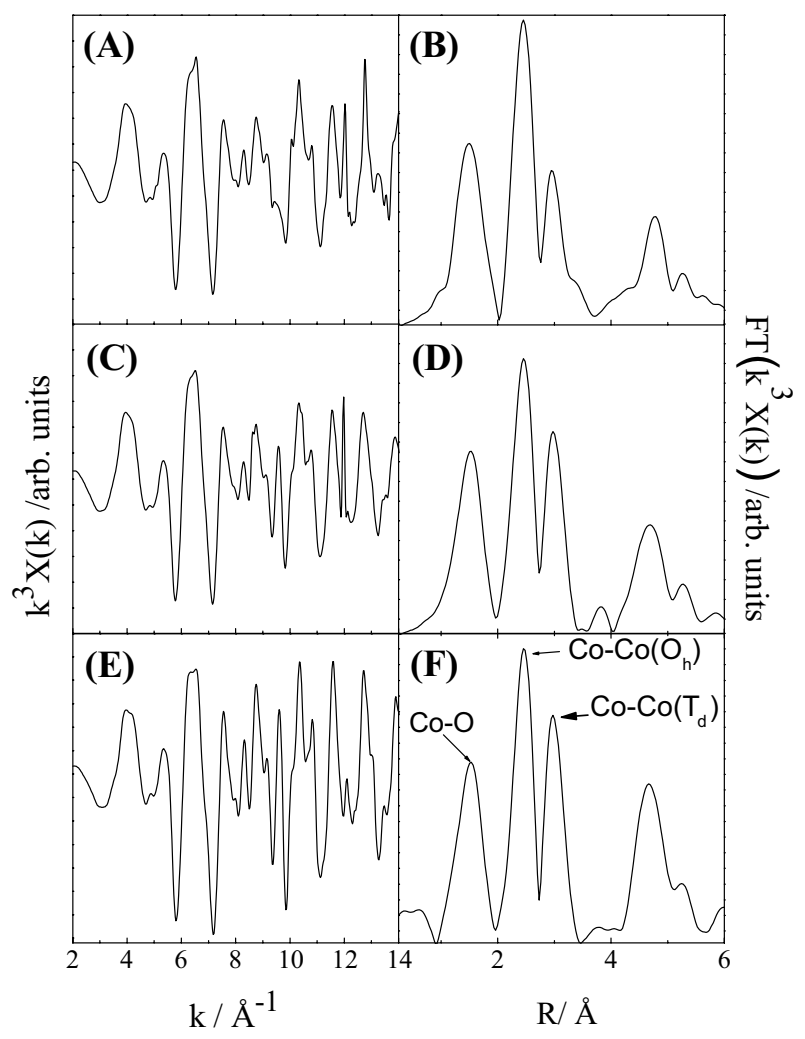

Fig. 6 EXAFS signal and their Fourier transform for sample (a-b) $\mathrm{Co} / \mathrm{M}(5),(\mathbf{c}-\mathbf{d}) \mathrm{Co} / \mathrm{M}(10)$ and the standard $(\mathbf{e}-\mathbf{f}) \mathrm{Co}_{3} \mathrm{O}_{4}$

On the other hand, at higher metal loading, the segregation of the oxide nanospecies of bigger size with more defined crystalline structure is enhanced. This could be related to the fact that the presence of $\mathrm{Co}_{3} \mathrm{O}_{4}$ was evidenced by XRD for theoretical Co loadings of 10 and $15 \mathrm{wt} \%$ and not for the smaller metal loadings.

Then, the chemisorption of pyridine followed by FT-IR studies was used to detect the presence and nature of acid sites on the synthetized solids [49-52]. Figure 7 shows the FT-IR spectra of the $\mathrm{Co} / \mathrm{M}(\mathrm{x})$ samples, recorded after the adsorption of pyridine and subsequent evacuation at 473 and $573 \mathrm{~K}$. It is important to note that in order to make a semi quantitative and comparative analysis, all the curves were affected by the pellet mass. It is known that pyridine is a basic molecule that can interact with acid sites via the nitrogen lone-par electrons giving rise to different characteristic bands. Thus, these bands give information about the strength of Lewis and Brönsted acid sites. It can be observed that all samples show two bands at 1597 and $1447 \mathrm{~cm}^{-1}$ corresponding to pyridine bonded to silanol groups whose hydroxyls are not capable of protonating pyridine [53-57]. These are the only bands found for the pure MCM- 41 which disappear upon evacuation at $573 \mathrm{~K}$ indicating the weak interaction between pyridine and the $\mathrm{Si}-\mathrm{OH}$ groups. For the Co containing solids, a band at $1610 \mathrm{~cm}^{-1}$ corresponding to pyridine coordinately bonded to Lewis acid sites [50, $53,56-60]$ could be observed, which is increasing proportionally with the Co loading. This band would be arising from the formation of a strong "electron-donor-acceptor" adduct between pyridine and Lewis sites, which result enough strong to retain pyridine even at $573 \mathrm{~K}$. In addition, the systematic increase of the band at $1447 \mathrm{~cm}^{-1}$ and its spectral shift towards higher wavenumber with the growing Co loading, could be interpreted in terms of the overlapping of
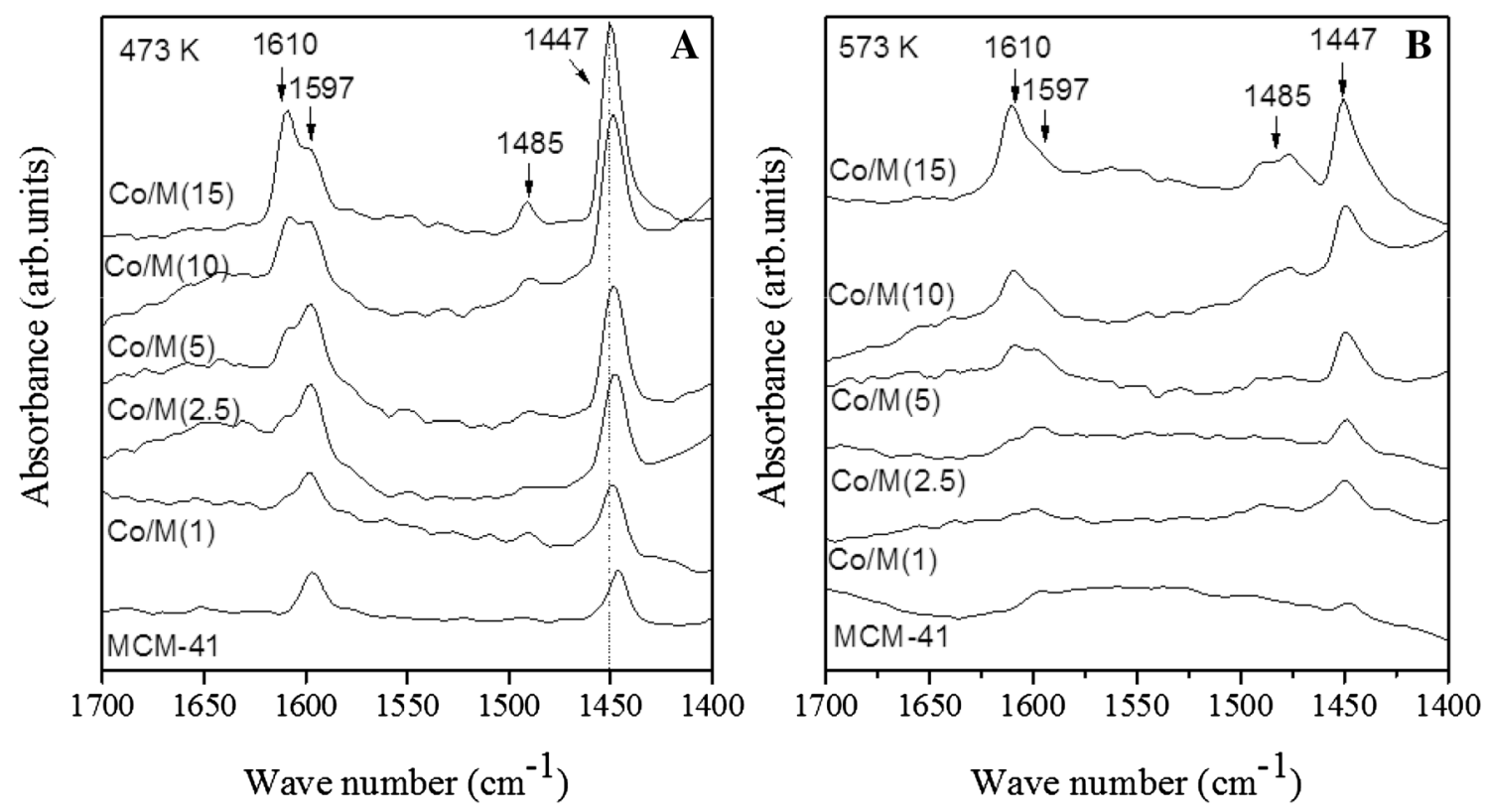

Fig. 7 FT-IR pyridine adsorbed on the samples $\mathrm{Co} / \mathrm{M}(\mathrm{x})$ and the bare MCM-41 material after evacuation at: a $473 \mathrm{~K}$ and b $573 \mathrm{~K}$ 
both the hydrogen-bonded pyridine band $\left(1447 \mathrm{~cm}^{-1}\right)$ and a band attributed to the Lewis-type adduct which frequently appears at $1450 \mathrm{~cm}^{-1}$ [58]. In fact, the retention of this band until $573 \mathrm{~K}$ only for the $\mathrm{Co} / \mathrm{M}(\mathrm{x})$ samples provides clear evidence that such band has a contribution from Lewis acid sites. Therefore, it is possible to suggest that the incorporation of Co in the siliceous matrix generates Lewis acid sites on the surface, which increase with the Co content. The origin of such Lewis acidity could arise from Co unoccupied molecular orbitals present in both the isolated Co species, coordinated to framework oxygen atoms in the channels, and the Co oxide species. Meanwhile, not all of the samples show bands at 1540 and $1636 \mathrm{~cm}^{-1}$ characteristic of Brönsted acid sites [60]. Therefore, the band observed at $1485 \mathrm{~cm}^{-1}$ in the $\mathrm{Co} / \mathrm{M}(\mathrm{x})$ samples, frequently assigned to pyridine associated with both, Lewis and Brönsted acid sites, corresponds only to Lewis acid sites.

Considering the spectra of the samples in the hydroxyl range (Fig. 8), for samples with Co loading up to $5 \mathrm{wt} \%$, it can be observed the presence of a band at $3740 \mathrm{~cm}^{-1}$ corresponding to the stretching vibrations of isolated terminal hydroxyl groups [26, 61-65].

Nevertheless, its decreased intensity with respect to the bare MCM- 41 could be attributed to the condensation of some $\mathrm{Si}-\mathrm{OH}$ groups with $\mathrm{Co}$ species leading to $\mathrm{Si}-\mathrm{O}-\mathrm{Co}$ bonds as well as to their partial blocking by the presence of some Co oxide clusters [66]. In addition, a broad contribution between 3700 and $3400 \mathrm{~cm}^{-1}$ that appears for the $\mathrm{Co} / \mathrm{M}(\mathrm{x})$ samples with lower metal content could be assigned to the interaction between vicinal $\mathrm{OH}$ groups, as $\mathrm{Si}-\mathrm{OH}$ and $\mathrm{Co}-\mathrm{OH}$ groups [67]. Finally, the fact that the absorbance corresponding to the $\mathrm{OH}$ groups is strongly diminished

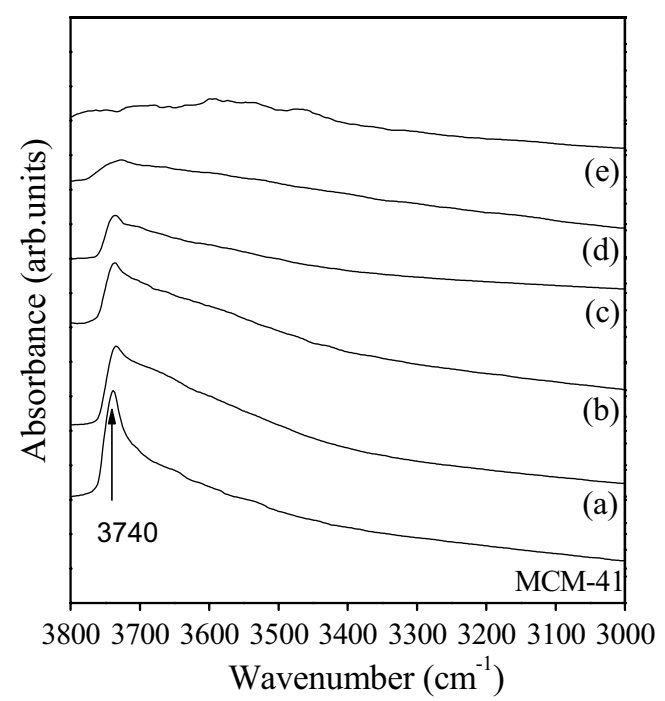

Fig. 8 FT-IR spectra in the hydroxyl stretching region after degassing at $673 \mathrm{~K}$ for samples: (a) $\mathrm{Co} / \mathrm{M}(1),(b) \mathrm{Co} / \mathrm{M}(2.5)$, (c) $\mathrm{Co} / \mathrm{M}(5)$, (d) $\mathrm{Co} / \mathrm{M}(10),(e) \mathrm{Co} / \mathrm{M}(15)$ for the samples with higher Co content $[\mathrm{Co} / \mathrm{M}(10)$ and $\mathrm{Co} / \mathrm{M}(15)]$ is likely due to enhanced amount of oxide nanospecies which could be blocking the silanols, besides contributing to the Lewis acidity $[68,69]$.

In a previous report [15], the analysis of the curves of magnetization $v s$ applied field, corresponding to the $\mathrm{Co} / \mathrm{M}(\mathrm{x})$ samples, showed that the superparamagnetic contribution exhibit a maximum for a theoretical Co loading of $2.5 \mathrm{wt} \%$. This behavior could be attributed to the presence of small Co nanospecies finely dispersed on the matrix. These species become larger for the higher Co loadings resulting in the decrease of the superparamagnetic contribution. In order to continue with this analysis, measurements of the temperature dependence of the magnetization were performed. Figure 9 shows the zero-field-cooling (ZFC) and field-cooling (FC) curves for the $\mathrm{Co} / \mathrm{M}(2.5)$ sample, measured with an applied field of 0.01T. For this sample, a reversal behavior was observed for temperatures higher than $\sim 150 \mathrm{~K}$. Under this temperature, the magnetic system shows irreversibility with a maximum in the $\mathrm{ZFC}$ curve $\left(\mathrm{T}_{\mathrm{B}}=4 \mathrm{~K}\right)$, which is associated with a distribution in the blocking temperatures of nanoparticles of different size. Therefore, considering an Arrhenius type relaxation for non-interacting nanoparticles, the $<\mathrm{T}_{\mathrm{B}}>$ corresponds to the blocking of an average volume:

$\ln \left(\tau_{\mathrm{m}} / \tau_{\mathrm{o}}\right) \mathrm{T}_{\mathrm{B}} \mathrm{k}_{\mathrm{B}}=\mathrm{KV}$

where $\mathrm{K}$ is the effective anisotropy constant, $\mathrm{k}_{\mathrm{B}}$ is the Boltzmann constant, $\tau_{\mathrm{m}}$ is the measure time ( $\tau_{\mathrm{m}} \sim 100 \mathrm{~s}$ for SQUID measurements) and $\tau_{\mathrm{o}}$ is the measurement time characteristic of the nanoparticles $\left(\tau_{\mathrm{o}} \sim 10^{-11}-10^{-9} \mathrm{~s}\right)$. Takada et al. [70] reported that superparamagnetic nanoparticles of $\mathrm{Co}_{3} \mathrm{O}_{4}$

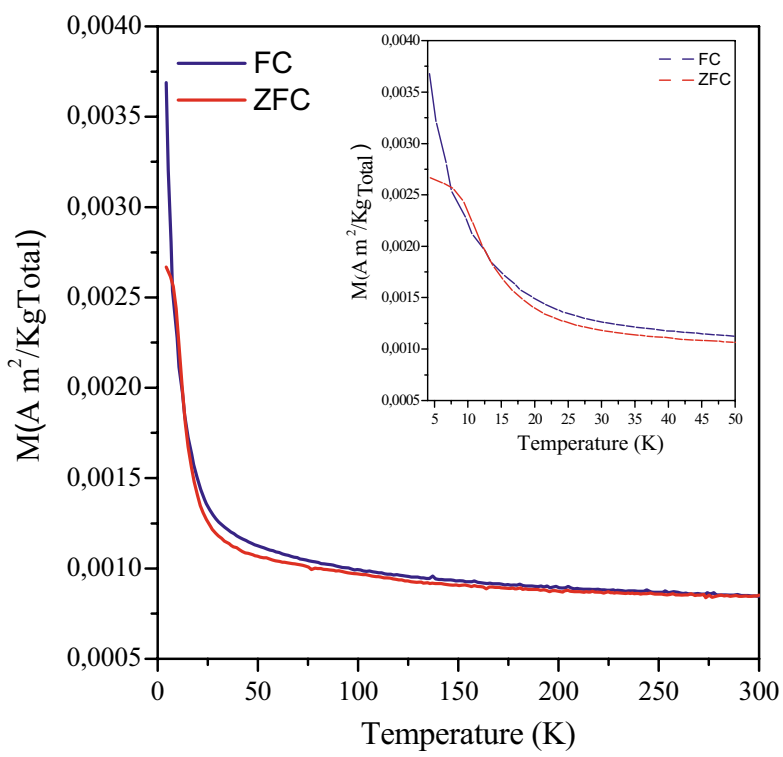

Fig. 9 Temperature dependence of the magnetization in the ZFC and FC states for an applied field for $\mathrm{Co} / \mathrm{M}(2.5)$ 
dispersed on amorphous $\mathrm{SiO}_{2}$ matrix, with a size of around $3 \mathrm{~nm}$, showed a $\mathrm{T}_{\mathrm{B}}$ of $3.4 \mathrm{~K}$ and $\mathrm{K}$ of $9 \times 10^{5} \mathrm{erg} \mathrm{cm}^{-3}$. In this sense, the $\mathrm{T}_{B}$ of around $4 \mathrm{~K}$ observed for the $\mathrm{Co} / \mathrm{M}(2.5)$ sample (Fig. 9) allowed to infer a nanoparticle size consistent with the presence of $\mathrm{Co}_{3} \mathrm{O}_{4}$ inside the mesoporous of the MCM-41 matrix. This fact agrees with the statements arising from the results obtained by the other techniques. Considering the expected magnetic behavior in solids in order to be used in the controlled drug delivery systems a Co loading of $2.5 \mathrm{wt} \%$ lead to an adequate material for hosting drugs in their structure. Thus, an improved performance in the field of the controlled release of medicaments could be achieved.

\section{Conclusions}

Several specific spectroscopic techniques were carefully applied in order to infer on the nature and location of different Co species formed on MCM-41 mesoporous silicates by a fast post synthesis method. All the analyses evidenced the presence of Co oxide nanospecies inside the pores of the mesostructure. Thus, TEM images showed that the pores are filled with the $\mathrm{Co}$ species from the darker regions along the channels. Nevertheless, for the higher Co loadings, $\mathrm{Co}_{3} \mathrm{O}_{4}$ nanoparticles segregated on the external surface of the silicate were also observed. In accordance, XPS evidenced the co-existence of $\mathrm{Co}^{2+}$ and $\mathrm{Co}^{3+}$ on the surface of the solids which could be assigned to the spinel cobaltite structure $\left(\mathrm{Co}_{3} \mathrm{O}_{4}\right)$ formed onto the mesoporous silicate. For all of the Co loadings, the surface $\mathrm{Co} / \mathrm{Si}$ atomic ratios were notably lower than the corresponding bulk $\mathrm{Co} / \mathrm{Si}$ ratios, indicating that the Co atoms are mostly incorporated inside the mesoporous channels of the silica matrix. In addition, comparing the XANES spectra of the $\mathrm{Co} / \mathrm{M}(\mathrm{x})$ samples with some standard substances of $\mathrm{Co}$, the presence of $\mathrm{Co}_{3} \mathrm{O}_{4}$ spinel on the MCM-41 silicates could be confirmed. With respect to the acidic properties of the synthesized materials, all of them showed a Lewis acidity increasing with the metal content. The presence of Lewis acid sites was assigned to both, the isolated Co species coordinated to framework oxygen atoms in the channels and Co oxide species. Finally, the results of the spectroscopic characterization and the presence of a $T_{B}$ of around $4 \mathrm{~K}$ in the $\mathrm{ZFC}$ curve for the $\mathrm{Co} / \mathrm{M}(2.5)$ sample, suggest that the Co oxide nanospecies of small size (clusters and $\mathrm{Co}_{3} \mathrm{O}_{4}$ nanoparticles) formed inside the MCM-41 mesopores are the responsible of notable superparamagnetic behavior. Such feature gives rise to solids with interesting properties for novel applications such as "drug hosting" for subsequent delivery through an external magnetic field. Therefore, these porous solids with improved performance result very promising in the field of the controlled release of medicaments.
Acknowledgements The authors are grateful to UTN-FRC and CONICET for the financial support. The authors also thank Ph.D Eliana Vaschetto and Ph.D Silvia Mendieta for assistance with the TEM/ SEM micrographs. Thanks are given to ANPCyT for the purchase of the SPECS multitechnique analysis instrument (PME8-2003).

\section{References}

1. A. Firouzi, S. Schaefer, B. Tolbert, G. Stucky, Chemelka magnetic-field-induced orientational ordering of alkaline lyotropic silicate-surfactant liquid crystals. J. Am. Chem. Soc. 119, 9466-9477 (1997)

2. P. Yang, T. Deng, D. Zhao, P. Feng, D. Pine, B. Chemelka, G. Whitesides, G. Stucky, Hierarchically ordered oxides. Science 282, 2244-2246 (1998)

3. C. Liang, Z. Li, S. Dai, Mesoporous carbon materials: synthesis and modification. Angew. Chem. 120, 3754-3776 (2008)

4. S. Zhu, H. Zhou, T. Miyoshi, M. Hibino, I. Honma, M. Ichihara, Self-assembly of the mesoporous electrode material $\mathrm{Li}_{3} \mathrm{Fe}_{2}\left(\mathrm{PO}_{4}\right)_{3}$ using a cationic surfactant as the template. Adv. Mater. 16, 20122017 (2004)

5. Y. Zhang, S. Zha, M. Liu, Duale-scale porous electrodes for solid oxide fuels cells from polymer foams. Adv. Mater. 17, 487-491 (2005)

6. L. Zhang, S. Qiao, Y. Jin, Z. Chen, H. Gu, G. Lu, Magnetic hollow spheres of periodic mesoporous organosilica and $\mathrm{Fe}_{3} \mathrm{O}_{4}$ nanocrystals: fabrication and structure control. Adv. Mater. 20, 805-809 (2008)

7. K. Nam, D. Kim, P. Yoo, C. Chiang, N. Meethong, P. Hammond, Y. Chiang, A. Belcher, Virus-enabled synthesis and assembly of nanowires for lithium ion battery electrodes. Science 312, 885888 (2006)

8. R.J. Farrauto, C.H. Bartholomew, Fundamental of Industrial Catalytic Processes (Blackie Academic and Professional, London, 1997), pp. 640-644

9. J. Spivey, J. Butt, Literature review: deactivation of catalyst in the oxidation of volatile organic compounds. Catal. Today 11, 465-500 (1992)

10. C. Dickinson, W. Zhou, R. Hodgkings, Y. Shi, D. Zhao, H. He, Formation mechanism of porous single-crystal $\mathrm{Cr}_{2} \mathrm{O}_{3}$ and $\mathrm{Co}_{3} \mathrm{O}_{4}$ templated by mesoporous silica. Chem. Mater. 18, 3088-3095 (2006)

11. B. Barbara, Single particle nanomagnetism. Solid State Sci. 7, 668-681 (2005)

12. K. Krishnan, A. Pakhomov, Y. Bao, P. Blomqvist, Y. Chun, M. Gonzales, K. Griffin, X. Ji, B. Roberts, Nanomagnetism and spin electronics: materials, microstructure and novel properties. J. Mater. Sci. 41, 793-815 (2006)

13. Q. Pankhurst, J. Commolly, S. Jones, J. Dobson, Applications of magnetic nanoparticles in biomedicine. J. Phys. D 36, 167-181 (2003)

14. V. Elías;, M. Crivello, E. Herrero, S. Casuscelli, G. Eimer, Some considerations to optimize the synthesis procedure and the structural quality of mesostructured silicas. J. Non-Cryst. Solids $\mathbf{3 5 5}$, 1269-1273 (2009)

15. N. Cuello, V. Elías, M. Crivello, M. Oliva, G. Eimer, Synthesis, characterization and magnetic behavior of $\mathrm{Co} / \mathrm{MCM}-41$ nanocomposites. J. Solid State Chem. 205, 91-96 (2013)

16. http://www.rigaku.com/xas/rxas.html

17. http://nano.fisica.unlp.edu.ar/facilities.php

18. A. Thenon, M. Mizrahi, L. Andrini, L. Giovanetti, J. RamalloLópez, F. Requejo, Comisionamiento del espectrómetro de absorción de rayos-X in house R-XAS Looper de RIGAKU, $21^{\mathrm{a}} \mathrm{RAU}$, Campinas, SP, Brasil (22 and 23 de february 2011) 
19. K. Shinoda, S. Zuzuki, M. Kuribayasi, T. Tasguchi, J. Phys. 186, $012036(2009)$

20. http://lnls.cnpem.br/beamlines/xafs/beamlines/xafs2/

21. http://bruceravel.github.io/demeter/

22. K. Choi, R. Wakabayashi, T. Tatsumi, T. Yokoi, K. Kuroda, Usefulness of alkoxyltitanosiloxane for the preparation of mesoporous silica containing a large amount of isolated titanium. J. Colloid Interface Sci. 359, 240-247 (2011)

23. Y. Xu, G. Zhou, C. Wu, T. Li, H. Song, Improving adsorption and activation of the lipase immobilized in amino-functionalized ordered mesoporous SBA-15. Solid State Sci. 13, 867-874 (2011)

24. A. Patterson, The Scherrer formula for X-ray particle size determination. Phys. Rev. 56, 978-982 (1939)

25. I. Park, J. Ha, J. Khim, Synthesis and characterization of visiblelight absorbing ordered mesoporous titanosilizate incorporated with vanadium oxide. Chem. Phys. Lett. 444, 161-166 (2007)

26. M. Moreno, M. Weyland, P. Midgley, J. Bengoa, M. Cagnoli, N. Gallegos, A. Alvarez, S. Marchetti, One-template synthesis of TiAl-containig mesoporous silicas and the application as potential photocatalytic degradation of chlorophenols. Micron 37, 52-56 (2006)

27. V. Elías, E. Sabre, E. Winkler, M. Satuf, E. Rodriguez-Castellón, S. Casuscelli, G. Eimer, Chromium and titanium/chromium-containing MCM-41 mesoporous silicates as promising catalystd for the photobleaching of azo dyes in aqueous suspensions. A multitechnique investigation. Microporous Mesoporous Mater. 163, 85-95 (2012)

28. X. Hao, Y. Zhang, J. Wang, W. Zhou, C. Zhang, S. Liu, A novel approach to prepare MCM-41 supported $\mathrm{CuO}$ catalyst with high metal loading and dispersion. Microporous Mesoporous Mater. 88, 38-47 (2006)

29. T. Tsoncheva, S. Areva, M. Dimitrov, D. Paneva, I. Mitov, M. Linden, C. Minchev, MCM-41 silica modified with copper and iron oxides as catalysts for methanol decomposition. J. Mol. Catal. A. 1-2 246, 118-127 (2006)

30. D. Yin, W. Li, W. Yang, H. Xiang, Y. Sun, B. Zhong, S. Peng, Mesoporous HMS molecular sieves supported cobalt catalyst for Fischer Tropsch synthesis. Microporous Mesoporous Mater. 47, 15-24 (2001)

31. V. Elías;, E. Sabre, K. Sapag, S. Casuscelli, G. Eimer, Influence of the $\mathrm{Cr}$ loading in $\mathrm{Cr} / \mathrm{MCM}-41$ and $\mathrm{TiO}_{2} / \mathrm{Cr} / \mathrm{MCM}-41$ molecular sieves for the photodegradation of Acid Orange 7. Appl. Catal. A. 413-414, 280-291 (2012)

32. J. Marco, J. Gancedo, M. Gracia, J. Gautier, E. Ríos;, H. Palmer, C. Greaves, F. Berry, Cation distribution and magnetic structure of the ferrimagnetic spinel $\mathrm{NiCo}_{2} \mathrm{O}_{4}$. J. Mater. Chem. 11, 3087-3093 (2001)

33. T. Baird, K. Campbell, P. Hollimen, R. Hoyle, M. Huxam, D. Stirling, B. Williams, M. Morris, Cobalt-zinc oxide absorbents for low temperature gas desulfurization. J. Mater. Chem. 9, 599-605 (1999)

34. J. Marco, J. Gancedo, M. Gracia, J. Gautier, E. Ríos, F. Berry, Characterization of Niquel Cobaltite $\mathrm{NiCo}_{2} \mathrm{O}_{4}$ Prepared by several methods: an XRD, XANES, EXAFS and XPS study. J. Solid State Chem. 153, 74-81 (2000)

35. B. Ernst, S. Libst, P. Chaumette, A. Kiennemann, Rock salt-spinel structural transformation in anodically electrodeposited Mn-Co-O nanocrystals. Appl. Catal. A 186, 145-168 (1999)

36. Y. Feng, L. Li, S. Niu, Y. Qu, Q. Zhang, Y. Li, W. Zhao, H. Li, J. Shi, Controlled synthesis of highly active mesoporous $\mathrm{Co}_{3} \mathrm{O}_{4}$ polycristals for low temperature $\mathrm{CO}$ oxidation. Appl. Catal. B 111-112, 461-466 (2012)

37. S. Shylesh, P. Samuel, A. Singh, Appl. Catal. A 318, 128-136 (2007)

38. A. Mottana, J. Robert, A. Marcelli, G. Giuli, G. Della Ventura, E. Paris, $\mathrm{Z}$. Wu, Octahedral versus tetrahedral coordination of $\mathrm{Al}$ in synthetic micas determined by XANES. Am. Mineral. 82 497-502 (1997)

39. T. Capehart, J. Herbst, R. Mishra, F. Pinkerton, X-ray-absorption edge shifts in rare-earth-transition-metal compounds. Phys. Rev. B 52, 7907-7914 (1995)

40. C. Engemann, J. Hormes, A. Longen, K. Dötz, An X-ray absorption near edge spectroscopy XANES study on organochromium complexes at the Cr K-edge. Chem. Phys. 237, 471-481 (1998)

41. X. Liu, C. Prewitt, High-temperature X-ray diffraction study of $\mathrm{Co}_{3} \mathrm{O}_{4}$ : transition from normal to disordered spinel. Phys. Chem. Miner. 17, 168-172 (1990)

42. M. Lelis, A. Porto, C. Gonçalves, J. Fabris, Cation occupancy sites in synthetic Co-doped magnetites as determined with X-ray absorption (XAS) and Mössbauer spectroscopies. J. Magn. Magn. Mater. 278, 263-269 (2004)

43. A. Serrano, E. Fernandez Pinel, A. Quesada, I. Lorite, M. Plaza, L. Pérez, F. Jiménez-Villacorta, J. de la Venta, M. MartínGonzález, J. Costa-Krämer, J. Fernandez, J. Llopis, M. García, Room-temperature ferromagnetism in the mixtures of the $\mathrm{TiO}_{2}$ and $\mathrm{Co}_{3} \mathrm{O}_{4}$ powders. Phys. Rev. B 79(1-5), 144405 (2009)

44. L. Bai, M. Pravica, Y. Zhao, C. Park, Y. Meng, S. Sinogeikin, G. Shen, Charge transfer in spinel $\mathrm{Co}_{3} \mathrm{O}_{4}$ at high pressures. J. Phys. 24(1-7), 435401 (2012)

45. T. Yamamoto, Assignment of pre-edge peaks in K-edge X-ray absorption spectra of $3 \mathrm{~d}$ transition metal compounds: electric dipole or quadrupole. X-Ray Spectrom. 37, 572-584 (2008)

46. T. Jiang, D. Ellis, X-ray absorption near edge structures in cobalt oxides. J. Mater. Res. 11, 2242-2256 (1996)

47. N. Koizumi, S. Suzuki, Y. Ibi, Y. Hayasaka, Y. Hamabe, T. Shindo, M. Yamada, J. Synch, Mechanism for enhancing dispersion of $\mathrm{Co}_{3} \mathrm{O}_{4}$ nanoparticles in $\mathrm{Co} / \mathrm{SiO}_{2}$ Fischer-Tropsch synthesis catalyst by adding glycol to impregnating solution: a quick-XAFS study. Rad 19, 74-83 (2012)

48. M. Ma, Z. Pan, W. Wang, L. Guo, J. Li, Z. Wu, S. Yang, Microstructure and gas-sensing property of the ordered mesoporous $\mathrm{Co}_{3} \mathrm{O}_{4}$. J. Nanosci. Nanotechnol. 13, 864-868 (2013)

49. C. Chanquía, L. Andrini, J. Fernández, M. Crivello, F. Requejo, E. Herrero, G. Eimer, Speciation of copper in spherical mesoporous silicates: from the Microscale to Angstrom. J. Phys. Chem. C 114, 12221-12229 (2010)

50. B. Chakraborty, B. Viswanathan, Surface acidity of MCM-41 by in situ IR studies of pyridine adsorption. Catal. Today 49, 253260 (1999)

51. M. Hunger, U. Schenk, M. Breuninger, R. Gläser, J. Weitkamp, Characterization of the acid sites in MCM-41-type materials by spectroscopic and catalytic techniques. Microporous Mesoporous Mater. 27, 261-271 (1999)

52. X. Zhao, G. Lu, A. Whittaker, G. Millar, H. Zhu, Comprehensive study of surface chemistry of MCM-41 Using ${ }^{29} \mathrm{Si}$ CP/MAS NMR, FTIR, Pyridine-TPD, and TGA. J. Phys. Chem. B 101, 6525-6531 (1997)

53. T. Conesa, J. Hidalgo, R. Luque, J. Campelo, A. Romero, Influence of the acid-base properties in Si-MCM-41 and B-MCM41 mesoporous materials on the activity and selectivity of e-caprolactam synthesis. Appl. Catal. A 299, 224-234 (2006)

54. A. Jentys, K. Kleestorfer, H. Vinek, Concentration of surface hydroxyl groups on MCM-41. Microporous Mesoporous Mater. 27, 321-328 (1999)

55. G. Eimer, S. Casuscelli, C. Chanquia, V. Elías, M. Crivello, E. Herrero, The influence of Ti-loading on the acid behavior and on the catalytic efficiency of mesoporous Ti-MCM-41 molecular sieves. Catal. Today 133, 639-646 (2008)

56. D. Trong, S. Nguyen, V. Hulea, E. Dumitriu, S. Kaliaguine, Mono- and bifunctional MFI, BEA and MCM-41 titanium-molecular sieves. Part 1. Synthesis and characterization. Microporous Mesoporous Mater. 57, 169-180 (2003) 
57. D. Srinivas, R. Srivastava, P. Ratnasamy, Transesterifications over titanosilicate molecular sieves. Catal. Today 96, 127-133 (2004)

58. A. Sakthivel, S. Dapurkar, N. Gupta, S. Kulshreshtha, P. Selvam, The influence of aluminium sources on the acidic behavior as well as on the catalytic activity of mesoporous H-AlMCM-41 molecular sieves. Microporous Mesoporous Mater. 65, 177-187 (2003)

59. C. Otero, M. Areán, V. Rodríguez Delgado, J. Montouillout, C. Lavalley, J. Fenández, J. Cuart Pascual, Parra, NMR and FTIR spectroscopic studies on the acidity of gallia-silica prepared by a sol-gel route. Microporous Mesoporous Mater. 67, 259-264 (2004)

60. L. Cedeño, D. Hernández, T. Klimova, J. Ramírez, Synthesis of $\mathrm{Nb}$-containing mesoporous silica molecular sieves Analysis of its potential use in HDS catalysts. Appl. Catal. A 241, 39-50 (2003)

61. F. Gao, Y. Zhang, H. Wan, Y. Kong, X. Wu, L. Dong, B. Li, Y. Chen, The states of vanadium species in V-SBA-15 synthesized under different $\mathrm{pH}$ values. Microporous Mesoporous Mater. 110, 508-516 (2008)

62. Y. Segura, P. Cool, P. Kustroeski, L. Chmielarz, R. Dziembaj, E. Vansant, Characterization of vanadium and titanium oxide supported SBA-15. J. Phys. Chem. B 109, 12071-12079 (2005)

63. M. Anpo, M. Matsuoka, Y. Shioya, H. Yamashita, E. Gimello, C. Monterra, M. Che, H. Patterson, S. Webber, S. Ouellette, M. Fox, Preparation and characterization of the $\mathrm{Cu}+/ \mathrm{ZSM}-5$ catalyst and its reaction with NO under UV irradiation at $275 \mathrm{~K}$. In situ photoluminescence, EPR, and FT-IR investigations. J. Phys. Chem. 98, 5744-5750 (1994)
64. L. Chmielarz, P. Kustrowski, R. Dziembaj, P. Cool, E. Vansant, Catalytic performance of various mesoporous silicas modified with copper or iron oxides introduced by different ways in the selective reduction of NO by ammonia. Appl. Catal. B 62, 369380 (1994)

65. I. Babich, Y. Plyuto, P. Van der Voort, E. Vansant, Thermal transformations of chromium acetylacetonate on silica surface. J. Colloid Interface Sci. 189, 144-150 (1997)

66. P. Carraro, V. Elías, A. García Blanco, K. Sapag, S. Moreno, M. Oliva, G. Eimer, Synthesis and multi-technique characterization of nickel loaded MCM-41 as potential hydrogen-storage materials. Microprorous Mesoporous Mater. 191, 103-111 (2014)

67. M. Tamura, W. Chaikittisilp, T. Yokoi, T. Okubo, Incorporation process of $\mathrm{Ti}$ species into the framework of MFI type zeolite. Microprorous Mesoporous Mater. 112, 202-210 (2008)

68. L. Pierella, C. Saux, H. Bertorello, P. Bercoff, P. Botta, J. Rivas, Occluded cobalt species over ZSM-5 matrix: design, preparation, characterization and magnetic behavior. Mater. Res. Bull 43, 2026-2035 (2008)

69. D. Dumitriu, R. Barjega, L. Frunza, D. Macovei, T. Hu, Y. Xie, V. Parvulescu, S. Kaliaguine, BiOx clusters occluded in a ZSM-5 matrix: preparation, characterization, and catalytic behavior in liquid-phase oxidation of hydrocarbons. J. Catal. 219, 337-351 (2003)

70. S. Takada, M. Fujii, S. Kohiki, T. Babasaki, H. Deguchi, M. Mitome, M. Oku, Intraparticle magnetic properties of $\mathrm{Co}_{3} \mathrm{O}_{4}$ nanocrystals. Nano Lett. 1, 379-382 (2001) 